\title{
The NARC (Nonsteroidal Anti-inflammatory in Renal Colic) Trial. Single-dose intravenous ketorolac versus titrated intravenous meperidine in acute renal colic: a randomized clinical trial
}

\author{
Victor M. Wood, MD; $* \dagger$ James M. Christenson, MD;* $*$ Grant D. Innes, MD;* $* \S$ \\ Mary Lesperance, PhD; $[$ R. Douglas McKnight, MD***
}

\begin{abstract}
Objectives: Intravenous (IV) opioid titration is an accepted method of relieving acute renal colic. Studies have shown that nonsteroidal anti-inflammatory drugs (NSAIDs) are also effective in this setting. Our objective was to compare single-dose ketorolac and titrated meperidine, both administered intravenously, with respect to speed and degree of analgesia, adverse effects and functional status. Our primary hypothesis was that these agents provide equivalent analgesia within 60 minutes. Our secondary hypotheses were that ketorolac-treated patients would experience fewer adverse effects and would be better able to resume usual activity.

Methods: This was a multicentre, double-blind randomized equivalence trial in a convenience sample of patients age 18-65 with moderate or severe renal colic, documented by intravenous pyelogram, ultrasound or stone passage. Meperidine-treated patients received $50 \mathrm{mg}$ IV meperidine at 0 minutes, then $25-50$ mg every 15 minutes as needed for ongoing pain. Ketorolac-treated patients received $30 \mathrm{mg}$ IV ketorolac at 0 minutes and placebo injections every 15 minutes as needed. Pain levels and adverse effects were assessed every 15 minutes, and functional status was evaluated at 60 minutes. Our primary outcome was the proportion of patients with mild or no pain at 60 minutes. Results: Overall, 49 of 77 meperidine-treated patients $(64 \%$; $95 \%$ confidence interval [CI], $53 \%-75 \%)$ and 47 of 65 ketorolac-treated patients ( $72 \% ; 95 \% \mathrm{Cl}, 61 \%-83 \%)$ achieved successful pain relief at 60 minutes ( $p$ value for equivalence $=0.002$ ). Ten percent of meperidine-treated patients and $44 \%$ of ketorolac-treated patients were able to resume usual activity at 60 minutes $(p=0.001)$.
\end{abstract}

Conclusions: In the doses studied, single-dose IV ketorolac is as effective as titrated IV meperidine for the relief of acute renal colic and causes less functional impairment.

\section{RÉSUMÉ}

Objectif : Le titrage intraveineux (i.v.) d'opioïdes est une méthode reconnue pour soulager la colique néphrétique aiguë. Des études ont démontré que les anti-inflammatoires non stéroïdiens sont également efficaces dans cette situation. Notre objectif était de comparer le kétorolac à dose

From *the Department of Surgery, University of British Columbia, Vancouver, BC; +Royal Jubilee Hospital, Victoria, BC; $¥$ St. Paul’s Hospital, Vancouver; §Royal Columbian Hospital, New Westminster, BC; ๆthe Department of Mathematics and Statistics, University of Victoria, Victoria; and **Vancouver Hospital, Vancouver.

This article has been peer reviewed. 
unique et la mépéridine titrée, tous deux administrés par i.v., quant à la vitesse et au degré d'analgésie, aux effets indésirables et au statut fonctionnel. Notre hypothèse principale était que ces agents offrent le même degré d'analgésie en moins de 60 minutes. Nos hypothèses secondaires étaient que les patients traités au kétorolac éprouveraient moins d'effets indésirables et seraient plus en mesure de reprendre leurs activités normales.

Méthodes: Il s'agissait d'une étude d'équivalence multicentrique randomisée en double insu chez un échantillon pratique de patients âgée entre 18 et 65 ans atteints de colique néphrétique de modérée à sévère, confirmée par une pyélographie intraveineuse, une échographie ou l'élimination d'un calcul. Les patients traités à la mépéridine reçurent $50 \mathrm{mg}$ i.v. de mépéridine à 0 minute, puis 25-50 mg toutes les 15 minutes au besoin, selon la douleur. Les patients traités au kétorolac reçurent $30 \mathrm{mg}$ i.v. de kétorolac à 0 minute, puis une injection de placebo toutes les 15 minutes au besoin. Les niveaux de douleur et les effets indésirables furent évalués toutes les 15 minutes et le statut fonctionnel fut évalué à 60 minutes. Notre résultat principal était la proportion de patients accusant une légère douleur ou aucune douleur à 60 minutes.

Résultats : Globalement, 49 des 77 patients traités à la mépéridine $(64 \%$; intervalle de confiance $[\mathrm{IC}]$ à $95 \%, 53 \%-75 \%)$ et 47 des 65 patients traités au kétorolac $(72 \%$; IC à $95 \%, 61 \%-83 \%)$ éprouvèrent un soulagement efficace de leur douleur à 60 minutes (valeur $p$ pour équivalence = 0,002 ). Dix pour cent des patients traités à la mépéridine et $44 \%$ des patients traités au kétorolac furent en mesure de reprendre leurs activités normales à 60 minutes $(p=0,001)$.

Conclusions: Pour les doses à l'étude, le kétorolac i.v. en dose unique est tout aussi efficace que la mépéridine i.v. titrée pour le soulagement de la colique néphrétique aiguë et cause moins de gêne fonctionnelle.

Key words: renal colic; ketorolac; meperidine; anti-inflammatory agents, nonsteroidal.

\section{Introduction}

Patients with renal colic often present to emergency departments with acute severe pain. Intravenous (IV) titration of opioid analgesics is a widely accepted method of providing rapid relief of severe pain; ${ }^{1}$ however, opioid titration is time consuming and requires more frequent nursing assessments than may be feasible. In addition, patients with renal colic often require higher opioid doses than many health care providers are comfortable administering. ${ }^{1}$ As a result, patients frequently receive inadequate analgesia. ${ }^{2}$ Those who do receive adequate opioid doses may experience adverse effects, particularly sedation, and a common observation is that many patients are unable to resume normal activities after treatment.

Several studies have demonstrated that nonsteroidal antiinflammatory drugs (NSAIDs) are effective in the treatment of renal colic. ${ }^{3-11}$ Ketorolac is effective for the treatment of renal colic, ${ }^{10,11}$ does not require close patient monitoring and is not associated with untoward sedation.

One case series showed that $30 \mathrm{mg}$ of IV ketorolac provided good relief from renal colic pain in 10 to 20 minutes. ${ }^{10}$ Another recent study suggested that single-dose IV ketorolac was superior to single-dose IV meperidine. ${ }^{11}$ Unfortunately, these studies do not consider the more relevant practice of opioid titration and, to date, no trials have compared single-dose IV ketorolac to titrated IV opioids in patients with acute renal colic.

This trial compares single-dose IV ketorolac to titrated IV meperidine in emergency department (ED) patients with acute renal colic. Our objectives were to compare the speed of onset and degree of analgesia offered by these agents, the incidence of adverse effects, and the patients' functional status 60 minutes after initial study drug administration.

Our primary hypothesis was that the 2 agents provide equivalent pain relief 60 minutes after commencement of therapy. Our secondary hypotheses were that the agents would provide equivalent pain relief at 15, 30 and 45 minutes, that patients receiving ketorolac would experience fewer adverse effects, and that patients receiving ketorolac would be able to resume usual activities more frequently than those receiving meperidine.

\section{Methods}

\section{Setting and patients}

We studied a convenience sample of patients aged 18 to 65 who presented to the emergency department at 1 of 4 urban teaching hospitals. Each participating ED was staffed by full time emergency physicians (EPs) and treated from 45,000 to 65,000 patients per annum. Patients were eligible for inclusion if they were experiencing self-described mod- 
erate to severe unilateral abdominal or flank pain that the treating EP suspected to be renal colic. Exclusion criteria included: pregnancy or breast-feeding; weight of less than $50 \mathrm{~kg}$ or more than $100 \mathrm{~kg}$; allergy to meperidine, ketorolac, dimenhydrinate, acetylsalicylic acid (ASA) or another NSAID; and history of peptic ulcer disease, gastrointestinal bleeding, perforation, or inflammatory bowel disease. To be eligible for efficacy analysis, patients required objective evidence of renal colic, including an intravenous pyelogram (IVP) or ultrasound, interpreted by a radiologist as showing hydronephrosis, hydroureter or a visible calculus on the affected side; or passage of a calculus that was subsequently inspected by a pathologist.

\section{Study design and treatments}

This was a randomized, double-blind clinical trial. All patients underwent initial examination to collect baseline demographics, to assess pain severity and to assure study eligibility. Consenting patients were stratified into 2 groups - moderate and severe - based on self-described pain severity. After stratification, subjects were randomly assigned to receive meperidine or ketorolac. The randomization scheme was computer-generated and randomization was done in blocks of 6 for each stratum.

At time zero, a blinded study nurse administered $5 \mathrm{cc}$ of study medication. Meperidine-treated patients received 50 $\mathrm{mg}$ of meperidine with $50 \mathrm{mg}$ of dimenhydrinate, and ketorolac-treated patients received $30 \mathrm{mg}$ of ketorolac. Study drugs were administered intravenously over $3 \mathrm{~min}-$ utes from identical, pre-prepared, numbered syringes. At $15,30,45$ and 60 minutes, subjects reported any adverse effects and documented their ongoing pain severity on visual analog and categorical scales.

At each 15-minute interval, additional IV study drug was given if ongoing pain was moderate or severe. Meperidinetreated patients received $25 \mathrm{mg}(2.5 \mathrm{cc})$ of meperidine if their pain was moderate and $50 \mathrm{mg}(5 \mathrm{cc})$ if it was severe. Ketorolac-treated patients received $2.5 \mathrm{cc}$ of saline placebo if their pain was moderate and $5 \mathrm{cc}$ if their pain was severe. In total, during the 1-hour study period, meperidine-treated patients received up to $200 \mathrm{mg}$ of meperidine and ketorolac-treated patients received $30 \mathrm{mg}$ of ketorolac. Our dosing regimen was based on a consensus of EPs as to what would commonly be used in practice. Patients were permitted to request rescue medication or drop out of the study at any time if pain relief was inadequate. The study period ended at 60 minutes.

This study was approved by the University of British Columbia's Investigational Review Board and by the research ethics committees of the participating hospitals.

\section{Efficacy, safety and tolerability assessment}

At 15-minute intervals after the initial injection of study medication, a research assistant collected the following data.

Categorical pain assessment: Subjects rated their ongoing pain as none, mild, moderate or severe on a verbal rating scale (VRS).

Visual analog scale (VAS) pain severity: Subjects marked their pain intensity on a non-demarcated $100-\mathrm{mm}$ horizontal line that had "no pain" written to the left and "most severe pain imaginable" to the right.

Adverse effects: Patients were asked to report any side effects and were asked specifically to grade nausea, vomiting, drowsiness, headache, dizziness, injection-site pain, dry mouth, nervousness, inability to concentrate, agitation, itching and sweating on a 4-point categorical scale: none, mild, moderate or severe.

Physiologic parameters: Blood pressure, pulse and respiratory rate were recorded.

Functional status: At the final clinical assessment (60 minutes), the research nurse and patient each rated the patient's ability to resume usual activities on a 3-point scale: not impaired (able to return to work and drive a car), mildly impaired (able to do activities of daily living at home), or severely impaired (confined to bed).

\section{End points and statistical analysis}

The primary end point was successful treatment, defined as the proportion of patients with a change in the VRS from severe or moderate to mild or none at 60 minutes after the first injection. This end point was determined a priori and was modeled after a pain study done on migraine treatment. ${ }^{12}$ Patients who withdrew from the study or requested rescue medication before the end of the study period were considered treatment failures.

The aim of the trial was to demonstrate therapeutic equivalence. Single-dose IV ketorolac was considered equivalent to titrated IV meperidine if the relative difference in successful treatment rates between the 2 agents was less than $20 \%$. The null hypothesis (of non-equivalence) was that the relative difference in successful treatment rates (meperidine vs. ketorolac) is greater than or equal to $20 \%$.

Secondary end points were VRS pain relief (from severe or moderate to mild or none) at 15, 30 and 45 minutes after the first injection; VAS pain scores at 15, 30, 45 and 60 minutes after the first injection; functional status, the proportion of subjects in each group who would be able to resume their usual activity (as assessed by the research nurse and by the patient) at 60 minutes after the first injection.

Based on a consensus of experienced EPs, we assumed that $80 \%$ of subjects would be successfully treated with 
meperidine. Accordingly, we calculated that a sample size of 63 patients per group was necessary to reject the null hypothesis of non-equivalence with a power of $80 \%$ at a one-sided 5\% significance level if the specified alternative hypothesis (of equivalence) was true.

For the primary end point, a one-sided $p$ value (testing for equivalence) and confidence intervals (CIs) are reported. The $p$ value for the primary end point was computed using the normal approximation to the test of equivalence given by Dunnett and Gent. ${ }^{13}$ For successful treatment and VAS scores at different time intervals, 95\% CIs are reported. For functional status and the incidence of side effects, $p$ values for chi-square tests of homogeneity are reported. SPSS 6.1.1 for the Mac was used for chi-square testing and to compute $95 \%$ CIs.

\section{Results}

\section{Patient population}

One hundred and ninety-five patients were enrolled and received study drug. One patient was excluded because of weight over $100 \mathrm{~kg}$, leaving 194 eligible for analysis. Of these, 137 had a diagnostic IVP or ultrasound, 5 passed a calculus and 52 lacked objective evidence of renal colic, leaving 142 eligible for efficacy analysis. At 15 minutes, 1 meperidine-treated patient and 1 ketorolac-treated patient dropped out because of inadequate pain control. At $30 \mathrm{~min}-$ utes, 4 meperidine-treated patients and 3 ketorolac-treated patients dropped out. At 45 minutes, 2 patients in each group dropped out, leaving 129 patients who completed the full study protocol.

\section{Baseline characteristics}

Baseline demographic and clinical data are summarized in Table 1 . The characteristics of the patients in the 2 groups

Table 1. Baseline characteristics of patients in the two groups

\begin{tabular}{|c|c|c|c|}
\hline \multirow{3}{*}{$\begin{array}{l}\text { Characteristic } \\
\text { No. of men (and \%) }\end{array}$} & \multicolumn{3}{|c|}{ Drug administered } \\
\hline & $\begin{array}{l}\text { Meperidine } \\
n=77\end{array}$ & \multicolumn{2}{|c|}{$\begin{array}{c}\text { Ketorolac } \\
n=65\end{array}$} \\
\hline & $68(88)$ & 57 & $(88)$ \\
\hline Mean age (and SD), yr & 40 (11) & 42 & (11) \\
\hline \multicolumn{4}{|l|}{ Race, \% } \\
\hline White & 74 & 77 & \\
\hline Black & 0 & 2 & \\
\hline Asian & 12 & 9 & \\
\hline Other & 14 & 12 & \\
\hline Mean weight (and SD), kg & $80.6(12.0)$ & 75.9 & $(1.8)$ \\
\hline Median pain duration (and IQR), $h$ & $3.5(2.0-6.0)$ & 3.5 & $(1.5-8.0)$ \\
\hline No. with moderate pain at study entry (and \%) & 24 & 17 & (26) \\
\hline No. with severe pain at study entry (and \%) & $53(69)$ & 48 & (74) \\
\hline Mean VAS at study entry (and $95 \% \mathrm{Cl}$ ) & $77.7(72.9-82.5)$ & 79.4 & $(75.1-83.7)$ \\
\hline
\end{tabular}

were similar, except for patient weight, which was greater in the meperidine-treated group.

\section{Actual meperidine doses}

Because meperidine was titrated to pain, the actual dose administered varied between patients. At 0 minutes, all patients received $50 \mathrm{mg}$. At 15 minutes, 19 patients received $50 \mathrm{mg}$ and 22 received $25 \mathrm{mg}$. At 30 minutes, 14 patients received $50 \mathrm{mg}$ and 19 received $25 \mathrm{mg}$. At 45 minutes, 10 patients received $50 \mathrm{mg}$ and 16 received $25 \mathrm{mg}$. The mean total meperidine dose administered during the 1-hour study period was $99 \mathrm{mg}$.

\section{Primary end point (Fig. 1)}

Successful treatment (VRS pain relief from severe or moderate to mild or none) at 60 minutes occurred in 49 of 77 (64\%; 95\% CI, 53\%-75\%) meperidine-treated patients and in 47 of $65(72 \%$; 95\% CI, 61\%-83\%) ketorolactreated patients ( $p$ value for equivalence $=0.002$ ). The difference in success rates (percentage of meperidine-treated patients compared to percentage of ketorolac-treated patients) was $-8 \%(95 \% \mathrm{CI},-23 \%$ to $7 \%$ ), favouring ketorolac.

\section{Other end points}

Figure 1 also shows treatment success rates by time. Overlapping confidence intervals at all time intervals indicate that differences between groups were not statistically significant. The $p$ values for equivalence were 0.05 at 15 minutes and less than 0.001 at 30 and 45 minutes, demonstrating statistical equivalence as defined above.

Figure 2 shows the proportion of patients, stratified by pain severity at study entry, who obtained adequate pain relief. There was a trend favouring ketorolac at all time intervals, even in patients with severe pain. Figure 3 shows VAS pain scores by treatment group at each time interval, demonstrating a similar trend.

Fifty-three patients were enrolled and treated, but were excluded from the efficacy analysis because they lacked objective evidence of urolithiasis $(n=52)$ or weighed more than $100 \mathrm{~kg}(n=1)$. A secondary analysis, including these patients, demonstrated the same relative analgesic efficacy as the primary analysis. 


\section{Functional ability}

Figure 4 shows that ketorolac-treated patients were more likely to be able to resume usual activity at study conclusion. Overall, $44 \%$ of ketorolac recipients vs. $10 \%$ of meperidine recipients rated themselves "unimpaired" at 60 minutes $(p<0.001)$. The research nurses' assessment of functional ability was similar, also favouring ketorolac.

\section{Safety and tolerability}

The most frequently occurring adverse events are shown in Table 2. There were no statistically significant differences

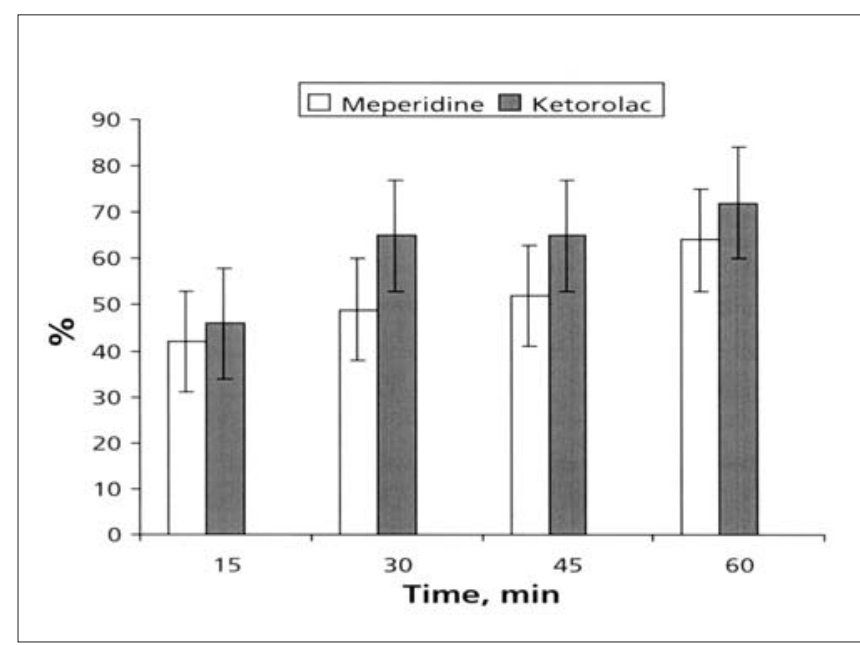

Fig. 1. Proportion of eligible patients $(n=142)$ with mild or no pain at different time intervals (and $95 \%$ confidence interval $[\mathrm{Cl}]$ )

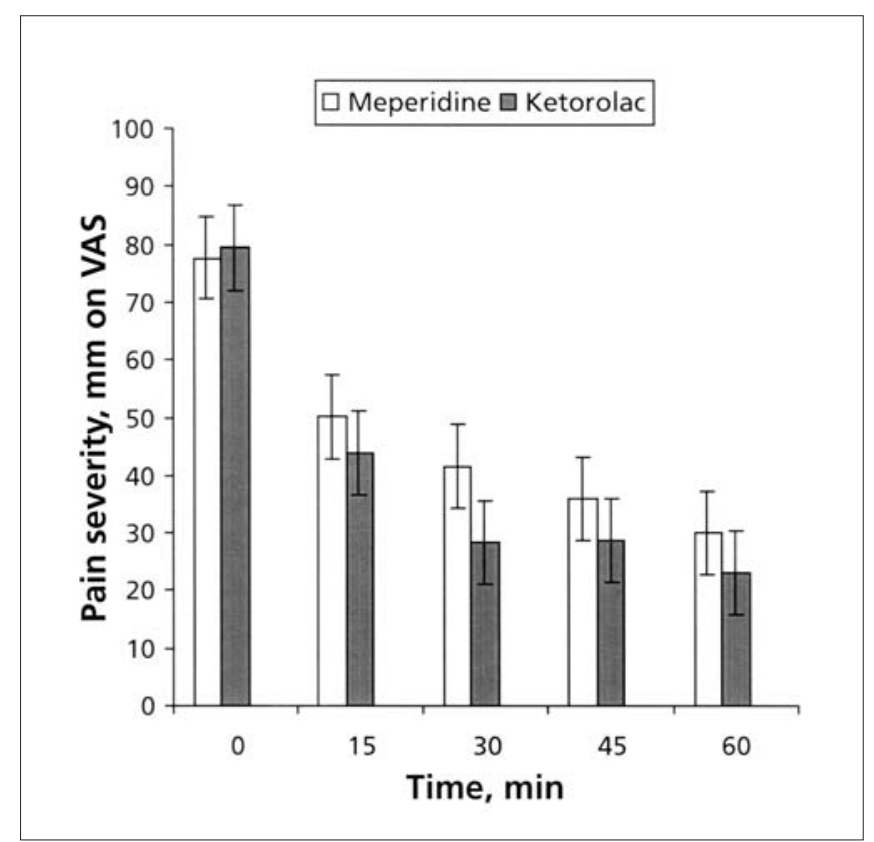

Fig. 3. Visual analog scale (VAS) pain severity at different time intervals for eligible patients $(n=142)$ (and $95 \% \mathrm{Cl}$ ) between treatment groups at any time interval for agitation, injection-site pain, itchiness, nausea, nervousness, sweating or vomiting.

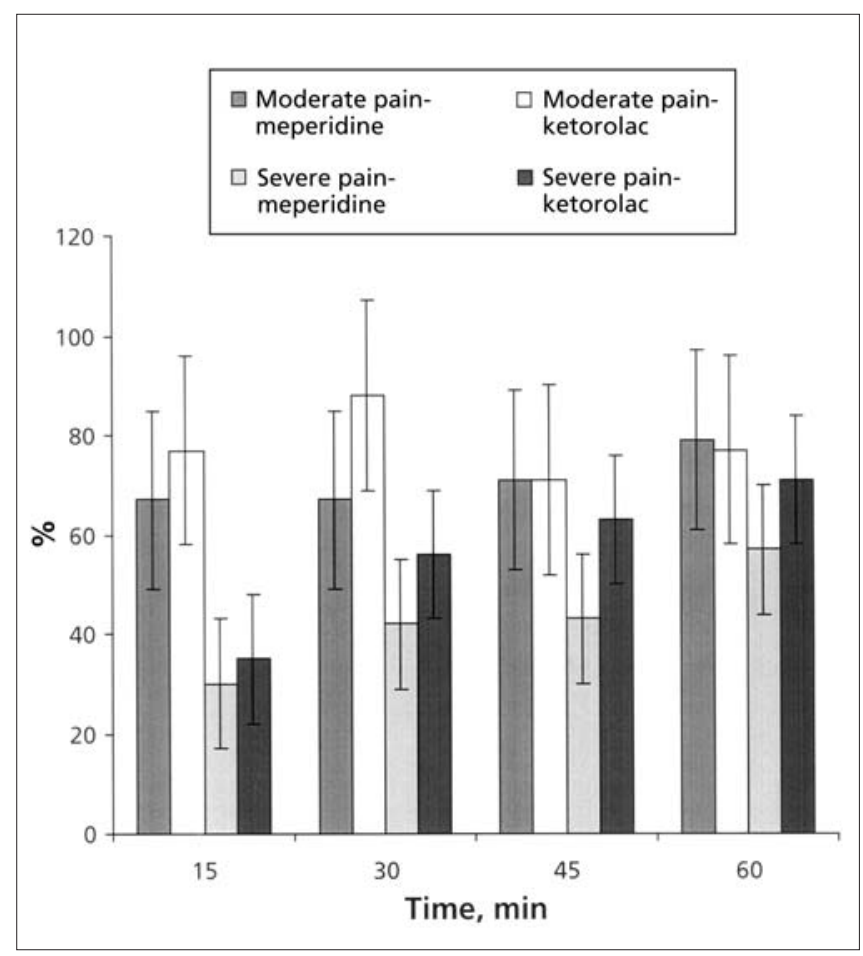

Fig. 2. Proportion of eligible patients $(n=142)$ stratified by level of pain at study entry who had mild or no pain at different time intervals (and $95 \% \mathrm{Cl}$ )

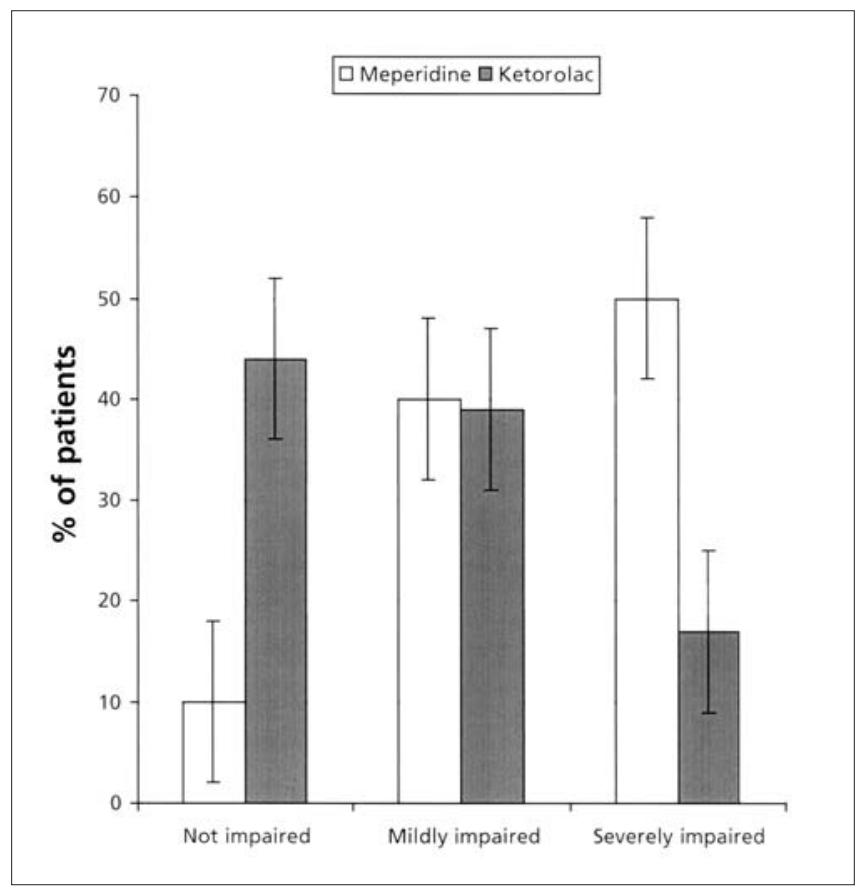

Fig. 4. Level of impairment (ability to resume usual activity) as assessed by the patient at 60 minutes (and 95\% Cl) 


\section{Discussion}

The aim of this multicentre trial was to determine whether single-dose IV ketorolac provides equivalent pain relief to titrated IV meperidine. We chose to perform an equivalence trial because we felt the 2 agents would have similar effectiveness and we thought that demonstrating equivalence would be more convincing than failing to show a statistically significant difference using a standard superiority trial. Many physicians will be unfamiliar with the statistical methodology of equivalence trials, and readers are referred to 2 recent thrombolytic trials ${ }^{14,15}$ that used designs similar to ours.

It is unlikely that any 2 agents are exactly equivalent, and to prove exact equivalence would require an infinite sample size. Therefore, when designing an equivalence trial, it is important to define a range of difference (or zone of indifference) that is accepted as "equivalent." A relative difference of $20 \%$ has been proposed ${ }^{16}$ as the criterion for declaring that an innovative therapy provides sufficient efficacy when tested against an active control; therefore, we defined equivalence as less than a $20 \%$ relative difference in successful treatment at 60 minutes. Our null hypothesis (of non-equivalence) was that meperidine is $20 \%$ better than ketorolac. Our research hypothesis (equivalence) was that meperidine is less than $20 \%$ superior. Consequently, if the upper limit of the $95 \%$ confidence range for the observed difference between drugs reached 20\%, with meperidine superior (one-sided test), we could not conclude equivalence.

In this study, $72 \%$ of ketorolac-treated patients and $64 \%$ of meperidine-treated patients experienced adequate analgesia. The absolute difference is $8 \%$, and the $95 \%$ CI around this difference extends from $-7 \%$ (meperidine superior) to $+23 \%$ (ketorolac superior). The corresponding range for relative success is $-11 \%$ (meperidine superior) to $+36 \%$ (ketorolac superior). Our calculated $p$ value for equivalence $(p=0.002)$ means there is a $0.2 \%$ chance of observing the difference we did, favouring ketorolac, if

Table 2. Number of moderate and severe adverse events at 60 minutes

\begin{tabular}{lccc} 
& \multicolumn{2}{c}{$\begin{array}{c}\text { No. (and \%) } \\
\text { of adverse events }\end{array}$} & \\
\cline { 2 - 3 } & $\begin{array}{c}\text { Meperidine } \\
n=91\end{array}$ & $\begin{array}{c}\text { Ketolorlac } \\
n=86\end{array}$ & $p$ value \\
\hline Adverse event & $45(50)$ & $6(7)$ & $<0.001$ \\
\cline { 2 - 3 } Drowsiness & $47(52)$ & $9(10)$ & $<0.001$ \\
Dry mouth & $17(19)$ & $1(1)$ & $<0.001$ \\
Dizziness & $24(26)$ & $3(3)$ & $<0.001$ \\
Inability to & & &
\end{tabular}

meperidine is actually $20 \%$ better. Therefore, based on our pre-specified criteria, we rejected the null hypothesis and accepted our research hypothesis, that the 2 treatments are statistically equivalent.

One of our secondary hypotheses was that the 2 treatments would also provide equivalent pain relief at 15,30 and 45 minutes. Figure 2 demonstrates that there was a trend favouring ketorolac at these time intervals, independent of whether the patient initially had moderate or severe pain.

We also hypothesised that ketorolac-treated patients would be better able to resume usual activity than meperidine-treated patients. Figure 4 shows that $44 \%$ of ketorolac recipients vs. $10 \%$ of meperidine recipients were judged able to resume usual activity at 60 minutes. At the same time, approximately $15 \%$ of ketorolac recipients and $50 \%$ of meperidine recipients were judged severely impaired. This impairment is primarily due to a statistically and clinically significant difference in adverse drug effects (Table 2), since VAS pain scores were not significantly different between groups (Fig. 3). These data suggest that meperidine's relatively poor performance was not related to underdosing, which is a criticism of many analgesic trials.

Patients in the meperidine-treated group were heavier than patients in the ketorolac group; however, a linear regression analysis showed no effect of weight on pain intensity at 60 minutes.

Our trial is the first to compare titrated intravenous meperidine to single-dose ketorolac. In a previous study, ${ }^{11}$ Cordell and colleagues demonstrated that single-dose IV ketorolac $(60 \mathrm{mg})$ provided better early analgesia than single-dose IV meperidine $(50 \mathrm{mg})$. In the Cordell study, VAS pain scores in meperidine-treated patients dropped from approximately $80 \mathrm{~mm}$ at baseline to $55 \mathrm{~mm}$ at 15 minutes, but did not improve further at 30 minutes. In the current study, meperidine-treated patients improved from a similar baseline to $50 \mathrm{~mm}$ at 15 minutes, then to $42 \mathrm{~mm}$ at $30 \mathrm{~min}$ utes (after patients with moderate or severe pain received additional meperidine). In the Cordell study, ketorolac recipients improved to $35 \mathrm{~mm}$ at 15 minutes and $25 \mathrm{~mm}$ at 30 minutes, whereas in the current study, ketorolac recipients improved to $44 \mathrm{~mm}$ at 15 minutes and $28 \mathrm{~mm}$ at 30 minutes. These differences are not clinically important, but it is possible that $60 \mathrm{mg}$ of ketorolac provides faster pain relief than the 30-mg dose we used.

A secondary analysis, including the patients who lacked objective evidence of urolithiasis, showed similar outcomes for efficacy, functional status and adverse effects, suggesting that our conclusions are robust and that IV ketorolac is effective for treating patients with "clinical" renal colic, whether or not confirmatory evidence is present. 
We believe that the results of this study apply to everyday practice, since the clinical and demographic characteristics of the study population were similar to those of most patients with renal colic.

\section{Limitations}

First, it is possible that some patients with extremely severe pain may not have entered the study and that these patients might have had a different response to analgesics; however, our data suggest that patients with severe pain responded at least as well to ketorolac as to meperidine. Second, like many ED studies, we used a convenience sample, which may have introduced a selection bias. Third, we do not know whether intravenous NSAID administration will provide more rapid pain relief than rectal administration. Finally, although the combination of effective analgesia and good functional status suggests that there are economic and productivity benefits to using IV ketorolac, we did not perform a formal economic analysis to demonstrate these benefits.

\section{Future research}

This study was underpowered $(B=0.73)$ to show a difference favouring ketorolac. A future study would require 417 patients per treatment arm to detect an $8 \%$ difference favouring ketorolac at the alpha $=0.05$ level with $80 \%$ power. Such a trial would be difficult to perform and of little clinical significance, since many clinicians prescribe analgesics in combination for patients with severe pain. A more important study would be an equivalence trial comparing IV ketorolac to "balanced" analgesia using an opioid/NSAID combination.

\section{Conclusions}

In the doses studied, single-dose ketorolac is as effective as titrated IV meperidine for the ED relief of acute renal colic. In addition, IV ketorolac causes fewer adverse effects and it better preserves the patient's functional ability 60 minutes after commencement of treatment.

Acknowledgement: This trial was carried out in the emergency departments of the Royal Columbian, St. Paul's and Vancouver hospitals, Vancouver, and the Royal Jubilee Hospital, Victoria, BC. It received grant support from the University Hospital Foundation and Hoffmann-La Roche Limited.

\section{References}

1. Rosen P, Barkin R, Danzl D, editors. Emergency medicine, concepts and clinical practice, 4th ed. St. Louis: Mosby Year-Book; 1998. p. 282.
2. Rosen P, Barkin R, Danzl D, editors. Emergency medicine, concepts and clinical practice, 4th ed. St. Louis: Mosby Year-Book 1998. p. 279

3. Lundstam S, Wahjander L, Kral JG. Treatment of ureteral colic by prostaglandin synthetase inhibition with diclofenac sodium. Cur Ther Res 1980;28:355-8.

4. Lundstam S, Wahjander L, Kral JG, Leissner K. Prostaglandin synthetase inhibition with diclofenac sodium in treatment of renal colic: comparison with use of a narcotic analgesic. Lancet 1982;1:1096-7.

5. Vignoni A, Fierro A, Moreschini G, Cau M, Agostino A, Daniele E, et al. Diclofenac sodium in ureteral colic: a double blind comparison trial with placebo. J Int Med Res 1983;11:303-7.

6. Grenabo L, Aurell M, Delin K, Holmlund D, Sjodin JG. Antidiuretic hormone levels and the effect of indomethacin on ureteric colic. J Urology 1983;129:941-3.

7. Sommer P, Kromann-Andersen, Lendorf A, Lyngdorf P, Moller P. Analgesic effect and tolerance of Voltaren and Ketogan in acute renal or ureteric colic. Br J Urol 1989;63:4-6.

8. Wolfson AB, Yealy DM. Oral indomethacin for acute renal colic. Am J Emerg Med 1991;9:16-9.

9. Thompson JF, Pike JM, Chumas PD, Rundle JSH. Rectal diclofenac compared with pethidine injection in acute renal colic. $\mathrm{Br}$ Med J 1989;299:1140-1.

10. Larsen LS, Miller A, Allegra JR. The use of intravenous ketorolac for the treatment of renal colic in the emergency department. Am J Emerg Med 1993;11:197-9.

11. Cordell WH, Wright SW, Wolfson AB, Timerding BL, Maneatis TJ, Lewis RH, et al. Comparison of intravenous ketorolac, meperidine, and both (balanced analgesia) for renal colic. Ann Emerg Med 1996;28:151-8.

12. The Subcutaneous Sumatriptan International Study Group. Treatment of migraine attacks with sumatriptan. N Engl J Med 1991;325:316-21.

13. Dunnett CW, Gent M. Significance testing to establish equivalence between treatments, with special reference to data in the form of 2X2 tables. Biometrics 1977;33:593-602.

14. The COBALT Investigators. A comparison of continuous infusion of alteplase with double-bolus administration for acute myocardial infarction. N Engl J Med 1997;337:1124-30.

15. Tebbe U, Michels R, Adgey J, Boland J, Caspi A, Charbonnier $\mathrm{B}$, et al. Randomized, double-blind study comparing saruplase with streptokinase therapy in acute myocardial infarction: The COMPASS equivalence trial. J Am Col Card 1998;31:487-93.

16. Ware JH, Antman EM. Equivalence trials. N Engl J Med 1997; $337: 1159-61$

Correspondence to: Dr. Victor M. Wood, Department of Emergency Medicine, Royal Jubilee Hospital, 1900 Fort St., Victoria BC V8R 1J8; vwood@pacificcoast.net 